\title{
Paulus og stoicismen
}

\section{Troels Engberg-Pedersen om kosmologi og pneumatologi hos Paulus}

\author{
Lektor, dr.theol. \\ Jan Dochhorn
}

Troels Engberg-Pedersen: Cosmology and Self in the Apostle Paul. The Material Spirit, Oxford: Oxford University Press 2010. XII + 287 s. $£ 27$ (paperback), £75 (indb.).

Abstract: Troels Engberg-Pedersen's Cosmology and Self in the Apostel Paul presents a philosophical exegesis of Paul which reconstructs a materialistic concept of Pneuma as a bodily entity and stresses the nonmetaphorical and concrete bodily meaning of theological, especially pneumatological concepts in the letters of Paul. TEPs theory about the material Pneuma and its Stoic backgrounds is criticised in this review whereas the impact of his focus on the non-metaphorical meaning of Pauline concepts (e.g. church as Christ's body) should not be underestimated. There is also a general theological potential in his claim that divine and human agency in Paul do not contradict one another.

Keywords: Paul, Stoicism, Pneuma, body, rhetorics, metaphor, sacramental reality, human freedom, anti-egoistic soteriology

Med denne bog fortsætter Troels Engberg-Pedersen (TEP) sine studier af Paulus og stoicismen og uddyber det, han kalder en filosofiskeksegetisk tilgang til Paulus. Han diskuterer især Paulus' kosmologi og dens paralleller i stoicismen og bruger Bourdieu og Foucault til at sætte hermeneutiske accenter. Jeg vil her fremhæve fire hovedtræk ved bogen og dernæst diskutere en række relaterede forskningsproblemer, bl.a. med inddragelse af tidligere reaktioner på bogen. ${ }^{1}$

1. Jf. J.M. Barclay: "Stoic Physics and the Christ-Event: A Review of Troels Engberg-Pedersen, Cosmology and Self in the Apostel Paul: ..." , JSNT 33 (2011), 406-414; J. Dunn: Anm.: Cosmology and Self etc., JTS 61 (2010), 748-750; A. Klostergaard Petersen: "Jeg er pneuma, lysende og stoflig", RVT 56 (2011), 98-103; J.R. Levison: "Paul in the Stoa Poecile: A Response to Troels Engberg-Pedersen, 


\section{Fire hovedtræk}

(1) TEPs filosofiske eksegese er åbenbart ikke blot et historistisk projekt, men har først og fremmest en hermeneutisk dimension. Han definerer filosofisk eksegese som "looking for ways of making sense of what Paul is saying in terms of the best available concepts, concepts that articulate a defensible world-view" (2). Disse koncepter finder TEP hos Foucault og Bourdieu, som især inddrages i bogens sidste kapitler. Henvisninger til paralleller mellem Paulus og stoicismen, der dominerer i de første fire kapitler, beviser i denne sammenhæng blot, at man kan interpretere Paulus med filosofiske kategorier. Dem henter TEP dog i nutidig filosofi frem for i stoicismen.

(2) Paulus er if. TEP forbundet med stoicismen bl.a. gennem en "materialistisk" ontologi, der især ses i pneumatologien: Pneuma er hos Paulus if. TEP en legemlig, materiel substans, der fysisk meddeles de troende, indvirker på deres legemer og gør dem til lemmer på en pneumatisk krop, der må forstås som en materiel entitet, identisk med kirken hhv. Kristi legeme.

TEP finder denne pneumatologi mange steder hos Paulus, men hans udgangspunkt er 1 Kor 15,35-49, hvor han bl.a. beskriver det pneumatiske legeme, som kristne får ved opstandelsen. TEP udlægger denne passage i kap. 1 (8-38). Det afgørende for ham er åbenbart det ekskursagtige afsnit om forskellige slags kød og herlighed $(\delta o ́ \xi \alpha)$ i 15,39-41, hvor især astral herlighed spiller en rolle (jf. 28). Afsnittet betragter TEP som en forberedelse af de efterfølgende meddelelser om de kristnes pneumatiske legeme. Dette er nemlig if. TEP i 15,4249 associeret med himlen ligesom de astrale entiteter, der nævnes i

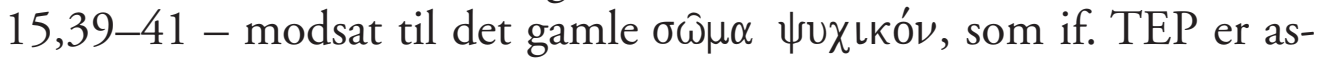
socieret med jordiske entiteter. Det pneumatiske legeme hos Paulus skal derfor opfattes som en himmelsk krop, der ligesom de astrale legemer adskiller sig fra jordiske legemer og er pneumatisk. Og at astrale legemer er pneumatiske, er en tanke, der er definitely stoic (jf. 28 og note 76 ).

(3) Paulus er if. TEP meget optaget af det legemlige: "I cannot think of anybody in antiquity who spoke so much about the body as Paul did", citerer han Wayne Meeks for (3), og så bliver Paulus' krop igen og igen tematiseret i denne bog, ikke mindst i kap. 5 og 6. Her udlægges Paulus' sociale aktivitet med Bourdieu som forsøget på at etablere en ny habitus. Og til habitus-teorien hører, at denne habitus ikke kun er relateret til andre mennesker, men også bundet til kroppen.

Cosmology and Self in the Apostle Paul", Journal for the Study of the New Testament 33 (2011), 415-432. 
Til den samme kategori hører tendensen til at fremhæve det konkrete hos Paulus: Mere end andre er TEP villig til at formode, at der ligger konkrete erfaringer bag, når Paulus taler $\mathrm{fx}$ om sin bortrykning til himlen (jf. 88-89 om 2 Kor 12,1-10).

Tilsvarende har udsagn, som andre eksegeter opfatter som metaforiske, for TEP ofte konkret betydning. Når Paulus fx taler om Kristi legeme, så bruger han for TEP ikke en metafor, men mener et materielt, pneumatisk legeme, der konkret omfatter alle kristne (169; 174).

(4) TEP bestræber sig for at ophæve dikotomier, der er nedarvede i vores eksegetiske og teologiske diskurser. En af disse er modsætningen mellem Guds og menneskets frihed (divine and human agency), som han gør op med i sin undersøgelse af Paulus og Epiktet i kap. 4: Vender mennesket sig mod Gud og bort fra de kosmiske magter, så betyder det for Paulus if. TEP ikke, at mennesket giver afkald på egen frihed i forhold til Gud, men at det udøver magt ved siden af Gud.

\section{Diskussion}

Der er gode grunde til at læse TEPs bog: Den er idérig, skrevet i et ambitiøst sprog, og kan danne udgangspunkt for en inspirerende debat. Her skal blot nævnes nogle aspekter, der lægger sig i forlængelse af ovenstående.

(1) Jeg savner i TEPs begreb om filosofisk eksegese klare afgrænsninger mellem eksegese og hermeneutik. Jeg betvivler ikke, at filosofiske kategorier er nødvendige for den i mine øjne centrale eksegetiske opgave, nemlig at rekonstruere en teksts oprindelige historiske intention. Det sker fx, når jeg overvejer, hvorvidt et europæisk-nordamerikansk standardverdensbillede (som normalt udelukker fx parafysiske teorier) hører til eksegesens forudsætninger. Men her befinder jeg mig på et område, som er traditionel eksegese velkendt, og forbliver inden for det store historistiske projekt.

Men det er noget ganske andet at spørge, om Paulus, som historiskfilologisk arbejde lader ham fremstå, stadig er an option for us - en ofte forekommende talemåde i bogen og åbenbart den vigtigste motivation for TEPs filosofiske eksegese. Dette spørgsmål hører for mig at se ikke til eksegesen, men til hermeneutikken, og grænsen herimellem må være metodisk klar. I øvrigt kan man spørge, om det hos TEP ikke snarere end Paulus er Bourdieu eller Foucault, der er an option for us.

(2a) TEPs eksegese af 1. Kor 15,35-49 blev allerede kritiseret af Barclay (Barclay 2011, 410-412). Jeg tilslutter mig kritikken, specielt 
pga. et forhold, som ikke passer til TEPs konstruktion: Såvel him-

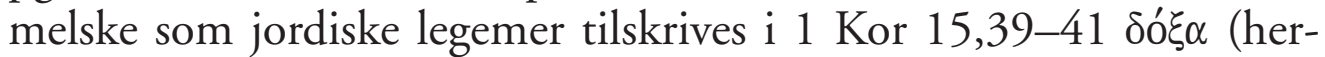
lighed). Det betyder, at en antitese mellem himmelsk og jordisk, som udelukkende tildeler $\delta o ́ \xi \alpha$ til astrale entiteter og kunne forbinde det

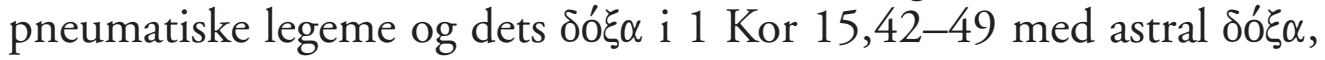
ikke findes i 1 Kor 15,40-41. Problematisk er også påstanden om, at det er definitely stoic at anse stjernerne som pneumatiske legemer (28). TEP skriver selv, at han ikke har et belæg (jf. 217, n 76). ${ }^{2}$

(2b) Man kan spørge, om der virkeligt er gode grunde til at føre det paulinske pneuma-begreb tilbage til stoicismen, selv hvis man betragter pneumaet hos Paulus som materielt. Det stoiske pneuma er en immanent guddommelig substans, der holder hele verden sammen ${ }^{3}$, mens den paulinske er en eskatologisk gave, der adskiller kristne fra andre mennesker.

(2c) På den anden side: Når Barclay imod TEP skriver om pneumaet som noget helt nyt i verden (Barclay 2011, 411), minder det om den moderne skelnen mellem transcendent og immanent, og man må spørge, om den i enhver henseende passer til Paulus. En af de store mulige gevinster ved TEPs projekt er, at den kan bidrage til en mere præcis beskrivelse af grænser og kontaktflader mellem "Guds verden" og skabelsen hos Paulus.

Til forskningen i pneumatologien hos Paulus hører spørgsmålet om, hvad det betyder, at Paulus ved siden af ånden/Guds ånd/Kristi ånd også kender andre ånder, som formodentlig er onde (Rom 11,8; 1 Kor 2,12; 1 Kor 12,10?), og derudover ånden som en antropologisk størrelse, der åbenbart ligner sjælen (Rom 1,9; 8,10.16; 1 Kor 2,11; 5,3.4.5; 7,34; 14,14; 16,18; 2 . Kor 2,13; 7,1.13; 1 Thess 5,23). Mht. den tidlige kristendom må man spørge: Hvorfor har vi i vores tekster ved siden af Guds ånd også urene ånder og ånden som en del af mennesket som helhed - bortset fra Gud selv, der også kan blive betegnet med ordet "ånd" (Joh 4,24)?

Jeg har forsøgt at forklare sammenhængen mellem Gud og ånderne vha. et fragment fra Assumptio Mosis, som blev bevaret af Gelasius

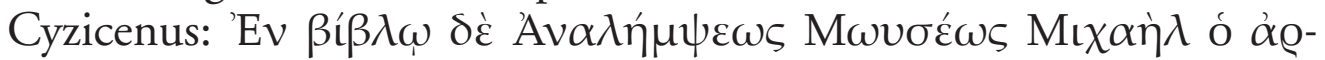

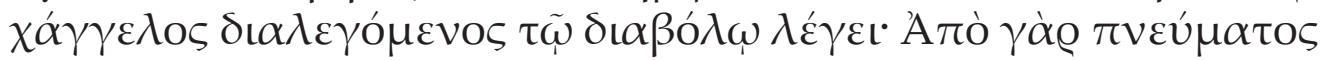

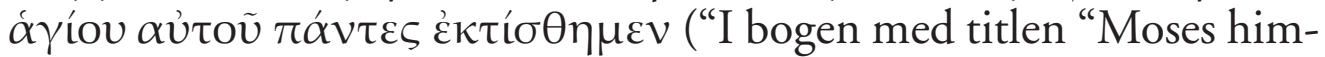
melfart" siger ærkeenglen Michael i sin diskussion med Djævlen: "Fra

2. De stoiske teorier vedrørende stjernernes væsen og materialitet kommer i bedste fald blot tæt på TEPs påstand, jf. Stoicorum Veterum Fragmenta (SVF). Red. H. von Arnim, Vol. IV (Leipzig: K.G. Saur 2004 [1924]), 29; 67-68; 127 (indekset sub verbis $\dot{\alpha} \sigma \tau \eta \rho$ (’’ $\sigma \tau \rho \circ \nu, \ddot{\eta} \lambda\llcorner\circ \varsigma$ og $\sigma \in \lambda \eta \dot{\eta} \nu \eta)$.

3. Jf. de belæg, som er samlet i SVF IV, 115-116 sub verbo $\pi \nu \in \hat{\mathrm{u} \mu \alpha .}$ 
hans [dvs. Guds] hellige ånd blev vi alle skabt"')). ${ }^{4}$ Her er sandsynligvis Guds hellige ånd den substans, som englene (samt djævlen, som er indbefattet i Michaels "vi") blev skabt fra. Desuden har vi tekster fra den tidlige jødedom, som muligvis implicerer, at man også forstod menneskets ånd (eller sjæl) som noget, der i sin substans hører til på Guds side, jf. Moses apok.- 31,4; 32,4; Visd 15,8.1; Ps-Phocylides 104-115; Filon, Legum Allegoria III, 161. Forståelsen bag kan beskrives således: Ånden i mennesket er identisk med subjektet (“jeg”); den blev mennesket tilegnet af Gud (som noget, der stammer fra Gud), og mennesket giver den tilbage ved døden. ${ }^{5}$

Dermed tegner sig formodentligt et verdensbillede, som udover en skelnen mellem Gud og skabelsen også kender en skelnen mellem et åndeligt og et ikke åndeligt univers. Og hvis Gud ligesom sin egen ånd selv er ånd (jf. Joh 4,24), så hører han også til et af disse universer. Én konsekvens er, at en del af skabelsen (den åndelige skabelse) mht. udgangsmaterialet hører til på Guds side. En anden er, at Gud ikke er fuldstændigt transcendent, idet han hører til et univers trods sin suverænitet som skaber.

Det viser sig nu, at det faktisk giver mening at spørge, om ånden i vores tekster er noget materielt. Men jeg tvivler på, om dette spørgsmål har meget med stoicismen eller hellenistisk filosofi at gøre: Allerede $\mathrm{i}$ traditionerne om vogterenglene arbejder man med en basal skelnen mellem "ånd" og "kød" (jf. fx 1 En 15). Hvad vogterenglene gjorde forkert, var at overskride denne grænse. Det, der adskiller englene fra mennesker, er deres substans eller - mere neutralt sagt - det "noget", de består af, nemlig "ånd", som muligvis skal betragtes som en materiel størrelse.

(3a) TEPs interesse for religiøs erfaring bliver kritiseret af A. Klostergaard Petersen, som"[ikke] forstår ..., hvordan TEP gennem retorisk gennemkomponerede tekster vil forsøge at nå bag om dem til en eller anden religiøs oplevelse". Men hvis vi går ud fra, at vores tekster har en Sitz im Leben, så er denne højest sandsynligt et socialreligiøst miljø, hvor andre oplevelser er mulige end dem, man kender i den vesteuropæiske middelklasse. Paulus selv omtaler uden den store

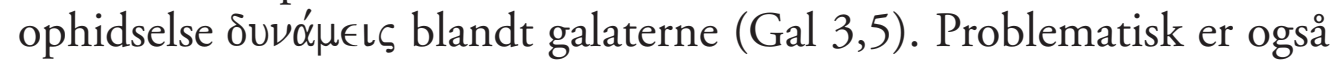

4. Jf. Jan Dochhorn: "Zu den religionsgeschichtlichen Voraussetzungen trinitarischer Gottesvorstellungen im frühen Christentum und in der Religion Israels", Trinität, red V.H. Drecoll, Themen der Theologie 2 (Tübingen: Mohr Siebeck 2011), 11-79(57-61). Fragmentet af Ass Mos citeres efter The Assumptio Mosis, red. C. Clemen (Cambridge: Deighton, Bell \& Co. 1904), 9-10; jf. The Assumption of Moses. A Critical Edition with Commentary, red. J. Tromp (Leiden: Brill 1993), 272. 5. Jf. Jan Dochhorn: "Vater, in deine Hände übergebe ich meinen Geist'. Das Kreuzeswort Jesu in Lk 23,46 und die Rezeption von Ps 31,6 im frühen Judentum und Christentum“, EC 2 (2011), 468-491. 
Klostergaards brug af ordet retorik, som minder lidt om den platonske antisofisme. Men retorik foregøgler ikke nødvendigvis en virtuel verden, der kun eksisterer i teksten.

(3b) TEPs tendens til en bogstavelig interpretation af paulinske udsagn, der generelt opfattes som metaforisk, bliver også kritiseret af både Klostergaard Petersen ${ }^{6}$ og Dunn (Dunn 2010, 750). Dunn kan $\mathrm{fx}_{\mathrm{x}}$ ikke tro, at den paulinske tale om kirken som Kristi legeme har andet end en metaforisk betydning. Men mod Dunn betvivler jeg, at metaforbegrebet er velegnet til at beskrive det omtalte ekklesiologiske koncept: For Paulus har kirkens (="vores") identitet som Kristi legeme formodentligt sin årsag deri, at "vi" som et offerfællesskab spiser fra ét og samme brød, hvilket er Kristi legeme (1 Kor 10,16-18). Man kunne med Paulus konkludere: Vi er, hvad vi spiser; og ligesom i Feuerbachs berømte vending har også denne sætning sandsynligvis en anden end en metaforisk betydning.

Måske kan en kategori fra den teologiske tradition her hjælpe videre: I den lutherske ortodoksi benytter man for at beskrive, hvad der sker, når man spiser Kristi legeme, kategorien manducatio sacramentalis. ${ }^{7}$ Denne kategori skal udelukke såvel en "figurativ" (= metaforisk og calvinistisk) som en "kapernaitisk" forståelse, der ville implicere kannibalisme. På en overnaturlig (sakramental) måde får mennesker i nadveren del i Kristi legeme. Talen om kirken som Kristi legeme er noget andet end debatten om de sakramentale elementer, men kategorien sacramentalis kan i mine øjne godt overføres til at betegne, hvad der menes med udsagnet, at "vi" er Kristi legeme: Vi er det faktisk og reelt, fordi nadveren, der konstituerer os som offerfællesskab, gør noget med os, som omdanner os til noget, der er ukendt i hverdags empiriske kategorier.

(4) Hvis frelse hos Paulus if. TEP ikke betyder, at mennesket giver afkald på sin egen aktivitet/subjektivitet (agency) i forhold til Gud,

6. Jf. Klostergaard Petersen (2011), 101-102. Her citeres en artikel af J.Z. Smith om metaforisering i en religiøs kontekst, som argumenterer med bororomænds forestilling om at være papegøjer og fremhæver det kontrafaktiske (og dermed "metaforiske") i denne forestilling, hvilket bl.a. viser sig deri, at bororomænd ikke forsøger at have samleje med "andre papegøjer". Klostergaard paralleliserer bororomænds påstand om at være papegøjer med TEPs Paulus, som ifølge Klostergaard godt kunne sige: "Jeg er pneuma, lysende og stoflig" (se titlen på hans artikel). Men TEPs Paulus har det dog bedre end bororomænd, idet han ikke bør bevise sin påstand gennem seksuel aktivitet. Han behøver blot henvise til, at han som et pneumatisk menneske fx en gang blev bortrykket til himlen. Åbenbart er det mere enkelt at være pneumatisk end at være en papegøje.

7. Jf. Leonhard Hutter: Compendium Locorum Theologicorum, red. W. Trillhaas, KlT 183, (Berlin: de Gruyter 1961, 104-105 (\$21,21-25)); David Hollatz: Examen Theologicum Acroamaticum, Vol. II, (Darmstadt: WBG 1971 [1707]), 225-231 (\$ III, 2,5,16). 
så udvikler TEP en tanke, som i mine øjne kan være frugtbar både for Pauluseksegese og teologi. Der er i den lutherske tradition en tendens til at identificere synden og dermed det, som overvindes gennem frelsen eller omvendelsen, med menneskets ønske om selvstændighed over for Gud (det tyske begreb er ofte Selber-Sein-Wollen). If. denne position er det at forlade sig på og ville bevare sig selv i forhold til Gud die Ursünde, og følgelig består frelsen i overvindelsen af tendensen til at holde fast ved sin subjektivitet over for Gud. Denne opfattelse findes allerede før lutherdommen, jf. den af Luther så højtagtede Theologia deutsch, som beskriver vejen til gudserkendelsen på følgende måde: "Wan yn wilcher creatur di $\beta$ volkommen bekant werden soll, da muß creaturlicheyt, geschaffenheit, icheyt, selbheyt, verlören werden unde tzu nichte." ${ }^{8}$ På lignende måde kan Luther anse Eigenliebe som ursynden, som fører til, at mennesket overtræder det første bud og hellere tilbeder sig selv end Gud. ' Denne forståelse manifesterer sig også i Pauluseksegesen: I Barths Römerbriefkommentar handler Rom 2,1-3 ikke om et menneske, som synder på samme måde som den, dette menneske fordømmer, men om mennesket generelt, som i sin hybris overfor Gud stoler på det egne: "Auch der Glaube, sofern er in irgendeinem Sinn mehr als Hohlraum sein will, ist Unglaube."10 Også Bultmann kan fortolke Paulus på denne måde: Han taler om "das eigenmächtige Verhalten des Menschen ..., der der eigenen Kraft und dem Verfügbaren vertraut", og nævner en jødisk Grundsünde, som består i, at jøderne vil oprette deres egen retfærdighed. ${ }^{11}$ I lutherdommen og protestantismen eksisterer en "anti-egoistisk" hamartiologi og en anti-egoistisk Pauluslæsning, som i vid udstrækning forstår frelsen som overvindelse af egoismen. Et syn på Paulus, som stiller spørgsmålstegn ved en nedarvet dikotomi imellem divine og human agency kan bidrage til at undersøge, om synden hos Paulus virkeligt har noget at gøre med Selber-Sein-Wollen.

8. Jf. Theologia deutsch, red. H. Mandel, (Leipzig: A. Deichert (G. Böhme) 1908), 9. 9. Jf. Paul Althaus, Die Theologie Martin Luthers (Gütersloh: Gütersloher Verlagshus $\left.{ }^{6} 1983\right), 131-135$.

10. Jf. Karl Barth, Der Römerbrief, neue Bearbeitung (Zürich: TVZ 1967 [1922]), 32. 11. Jf. Rudolf Bultmann: Theologie des Neuen Testaments (Tübingen: Mohr Siebeck

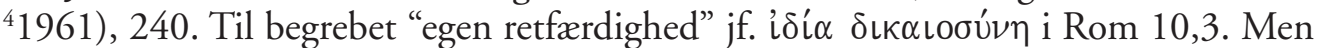
dér peger Paulus formodentligt ikke på egoisme (Selber-Sein-Wollen), men på det faktum, at jøderne med deres religiøse strategi har valgt det forkerte: en retfærdighed, som ikke kommer fra Gud, men fra mennesker (og derfor ikke er retfærdighed). 